\title{
PARENTING SKILL MENINGKATKAN PENGETAHUAN ORANGTUA TENTANG PEMBENTUKAN KARAKTER DISIPLIN ANAK PRASEKOLAH
}

\author{
Parenting Skill Increase Parents Knowledge about The Formation of Children's \\ Discipline Characters
}

\author{
Rizky Setiadi*, Andi Lis Arming Gandini, Umi Kalsum \\ Jurusan Keperawatan, Poltekkes Kemenkes Kalimantan Timur \\ Email Korespondensi: r12ky_ui@yahoo.com
}

\begin{abstract}
ABSTRAK
Karakter disiplin anak merupakan hal yang harus dibentuk sejak dini. Orang tua berperan utama dalam membentuk karakter disiplin pada anak, karenanya orang tua harus memiliki pengetahuan dan keterampilan yang memadai untuk melakukannya. Parenting skill merupakan salah satu upaya yang bisa dilakukan untuk dapat meningkatkan pengetahuan orang tua tentang pembentukan karakter disiplin pada anak. Penelitian ini merupakan penelitian analitik eksperimental dengan desain pretest and posttest without control group. Sampel yang diteliti sejumlah 41 ibu yang memiliki anak uia prasekolah terpilih menjadi responden dengan pengumpulan data sebanyak dua kali untuk mengetahui pengetahuan orang tua tentang pembentukan karakter disiplin pada anak preschool. Hasil uji wilcoxon rank test didapatkan adanya peningkatan nilai pengetahuan orang tua tentang pembentukan karakter disiplin pada anak sebelum dan sesudah diberikan pelatihan parenting skill (nilai p: 0.0001). perlu dilakukan upaya-upaya pemberian edukasi teknik parenting skill kepada orang tua untuk lebih meningkatkan pemahaman orang tua tentang pembentukan karakter disiplin pada anak, sehingga dapat tumbuh dan berkembang secara optimal dan memiliki karakter disiplin yang kuat.
\end{abstract}

Kata kunci : Parenting skill, disiplin, anak prasekolah

\section{ABSTRACT}

The character of a child's discipline must be formed early on. Parents had a major role in shaping the character of discipline in children, so parents must have adequate knowledge and skills to do so. Parenting skill is one of the efforts that can be done to increase parental knowledge about the formation of disciplinary character in children. This research is a quasi experimental analytic study with a pretest and posttest without control group design. The sample studied was 41 mothers of preschool children chosen as respondents by collecting data twice to find out the knowledge of parents about the formation of disciplinary character in preschool children. Based on wilcoxon rank test, there is a significant increase in the score of parental knowledge about the formation of disciplinary character in children before and after parenting skills training ( $p$ value: 0.0001). Efforts should be made to provide educational parenting skill techniques to parents to further enhance parents' understanding of the formation of disciplined characters in children, so that they can grow and develop optimally and have strong disciplinary characters.

Keywords : parenting skill, discipline, preschool children

\section{PENDAHULUAN}

Orang tua sebagai pendidik memiliki karakter dan sifat yang khas, antara orang tua yang satu dengan lain tidak bisa disamakan. Setiap orang tua memiliki cara tersendiri dalam berinteraksi, mendidik, dan mengarahkan anak yang disebut Parenting Skill. Parenting Skill orang tua merupakan pilar utama dalam mengasuh dan membimbing anak agar terwujudnya 
generasi yang berkarakter ${ }^{(1)}$.

Pendidikan karakter mempunyai makna lebih tinggi dari pada pendidikan moral, karena bukan sekedar mengajarkan mana yang benar dan mana yang salah, lebih dari itu pendidikan karakter menanamkan habit tentang mana yang baik dan buruk, mampu merasakan nilai yang baik dan bisa melakukannya. Jadi pendidikan karakter erat kaitannya dengan habit yang terus menerus dilakukan ${ }^{(2)}$.

Salah satu nilai karakter yang sangat penting dalam kehidupan adalah kedisiplinan. Kedisiplinan pada anak usia preschool dapat dipengaruhi oleh berbagai faktor yaitu faktor internal dan eksternal. Faktor internal antara lain jenis ras, jenis kelamin, kepribadian atau sifat bawaan anak, sedangkan faktor eksternal antara lain lingkungan, ekonomi keluarga, tipe pola asuh orang tua, status pekerjaan orang tua, tingkat pendidikan orang tua, jumlah anak dan kedudukan anak dalam keluarga $^{(3)}$.

Parenting Skill diartikan sebagai kemampuan yang dimiliki oleh orang tua dalam membesarkan dan mendidik anak sejak masih bayi hingga dewasa yang sangat berpengaruh terhadap perkembangan karakteristik anak pada nantinya. Perkembangan karakteristik pada anak meliputi perkembangan motorik, sosial kemandirian, bahasa, dan kedisiplinan salah satunya pada rutinitas harian $^{(4)}$.

Pada anak usia preschool $(0-6$ tahun) mempunyai tugas dan kewajiban antara lain melakukan rutinitas keseharian yang sehat (istirahat dan aktivitas), membangun kebiasaan makan yang baik, menguasai keterampilan dasar latihan toilet (toilet training), aktif berpartisipasi dalam kehidupan keluarga, belajar untuk berkomunikasi secara efektif dengan orang lain, dan belajar untuk menjadi pribadi mandiri dalam melakukan aktivitas dengan inisiatif dan dorongan dari dalam dirinya. Pada anak-anak yang terbiasa menjalankan rutinitas harian, akan terbentuk karakter yang disiplin pada diri anak ${ }^{(3)}$.

Permasalahan yang ditemukan saat ini banyak orang tua yang memarahi dan memukul anak dalam mendisiplinkan anaknya. Orang tua juga tidak mengatur dan menyusun rutinitas harian anak dalam sebuah aturan sehingga mereka cenderung akan membatasi eksplorasi dengan cara negatif ${ }^{(5)}$.

Menurut Global Report: Ending Violence in Childhood ditemukan bahwa tiap tahunnya terdapat 1,3 miliar anak di dunia usia 1-14 tahun telah mengalami kekerasan fisik di lingkungan rumah. Global Report: Ending Violence in Chilhood' juga melaporkan bahwa terdapat $73,7 \%$ anak Indonesia pernah mengalami kekerasan di rumahnya sendiri. Kekerasan yang di alami berupa pukulan dan cubitan yang biasa digunakan oleh orang tua kepada anaknya ${ }^{(6)}$.

Komisi Perlindungan Anak Indonesia (KPAI) melaporkan ada 1.000 kasus kekerasan pada anak dalam kurun waktu selama tahun 2016, dari catatan tersebut 55\% dari 702 laporan pelanggaran hak anak terkait keluarga dilakukan oleh ibu dalam upaya pendisiplinan anak. Angka kekerasan terhadap anak di Indonesia terus meningkat hingga pertengahan maret 2018 ada 1.980 laporan kekerasan terhadap anak di seluruh Indonesia $^{(7)}$.

Di Kalimantan Timur sendiri ditemukan kasus kekerasan pada anak, sepanjang 2016 terdapat 423 kasus kekerasan anak dan perempuan yang diterima Dinas Pemberdayaan Perempuan dan Perlindungan Anak (DPP PA) Samarinda. Laporan lain juga diterima oleh Pusat Pelayanan Terpadu Pemberdayaan Perempuan dan Anak (P2TP2A) Samarinda dan Komisi Perlindungan Anak Indonesia Daerah (KPAID) Samarinda ada 345 kasus. Angka itu meningkat dibandingkan tahun-tahun sebelumnya yang hanya ada di kisaran 200, hal tersebut 
mengindikasikan anak masih menjadi korban kekerasan dalam pendisiplinan ${ }^{(8)}$.

Salah satu faktor eksternal yang paling mempengaruhi kedisiplinan anak usia preschool yaitu pola asuh yang kurang tepat, hal itu didukung oleh hasil wawancara kepada orang tua ditemukan bahwa perlakuan orang tua ke anak yang tidak segan mencubit, menjewer, memukul anak, dan memarahi anak jika anak tidak mau menurut pada aturan orang tua. Penelitian yang dilakukan oleh Kalsum (2019), menunjukkan bahwa terdapat hubungan yang bermakna antara parenting skill dengan disiplin belajar anak ${ }^{(9)}$.

Penelitian ini bertujuan untuk mengetahui efektivitas pelatihan parenting skill terhadap pengetahuan orang tua tentang pembentukan karakter disiplin anak pra sekolah.

\section{METODE PENELITIAN}

\section{Desain}

Penelitian ini merupakan penelitian kuasi eksperimental dengan desain pretest and post test without control group. Intervensi yang diberikan berupa pelatihan parenting skill berupa kombinasi edukasi kesehatan dengan media Audio Visual Aid (AVA) dan metode ceramah serta diskusi yang dilakukan oleh trainer yang telah tersertifikasi. Intervensi dilakukan selama 90 menit di lokasi penelitian.

\section{Sampel Penelitian}

Penelitian ini dilakukan di salah satu Taman Kanak-kanak yang berada di Kota Samarinda. Jumlah sampel sebanyak 41 responden dengan teknik sampel populasi.

\section{Alat Pengukuran Data}

Instrumen penelitian yang digunakan dalam penelitian ini yaitu kuesioner dengan jumlah soal sebanyak 10 item pertanyaan. Pengumpulan data dilakukan sebelum dilakukan intervensi dan setelah dilakukan intervensi. Setelah dilakukan intervensi, dilakukan pengumpulan data pada keesokan harinya untuk mengidentifikasi pengetahuan responden terkait pembentukan karakter disiplin anak.

\section{Analisis Data}

Data dianalisis dengan menggunakan program komputer. Untuk mengetahui perubahan nilai pengetahuan orang tua tentang pembentukan karakter disiplin pada anak preschool dilakukan analisis bivariat dengan uji statistik berupa uji peringkat Wilcoxon.

\section{Etika Penelitian}

Penelitian ini telah disetujui oleh Komite Etik Penelitian Poltekkes Kemenkes Kalimantan Timur dengan SK No. LB.02.01/7.1/2755/2019 pada tanggal 05 Juli 2019.

\section{HASIL}

Karakteristik responden dapat dilihat pada tabel 1:

Tabel 1. Karakteristik Responden

\begin{tabular}{clcc}
\hline No & \multicolumn{1}{c}{ Variabel } & $\begin{array}{c}\text { Frek } \\
(\mathbf{N = 4 1 )}\end{array}$ & \% \\
\hline 1 & Usia: & & \\
& $<20$ tahun & 3 & 7.3 \\
& $21-30$ tahun & 6 & 14.6 \\
& $31-40$ tahun & 21 & 51.2 \\
& $>40$ tahun & 11 & 26.8 \\
\hline 2 & Tingkat Pendidikan & & \\
& Tidak Sekolah & 2 & 4.9 \\
& Dasar (SD/SMP) & 7 & 17.1 \\
& Lanjut (SMA/ Sederajat) & 23 & 56.1 \\
& Tinggi (Pendidikan & 9 & 22 \\
& Tinggi) & & \\
\hline 3 & Status Bekerja & & \\
& Tidak Kerja & 26 & 63.4 \\
& Bekerja & 15 & 36.6 \\
\hline Sumber: Data Primer, 2019
\end{tabular}

Sumber: Data Primer, 2019

Berdasarkan tabel 1, didapatkan bahwa responden yang berusia $31-40$ tahun sejumlah 21 orang $(51.2 \%)$. Pada tingkat pendidikan responden didapatkan sebagian besar telah menamatkan jenjang Sekolah Menengah Atas, namun masih ada yang tidak menyelesaikan pendidikan dasar. Sebagian besar responden tidak bekerja yatu sebesar $63.4 \%$. 
Tabel 2. Pengetahuan Responden tentang Pembentukan Karakter Disiplin Anak Preschool Tahun 2019

\begin{tabular}{ccccc}
\hline Pengetahuan & Min & Max & Median & SD \\
\hline Sebelum & 4 & 10 & 7 & 1.4 \\
Sesudah & 6 & 10 & 9 & 1.1 \\
\hline
\end{tabular}

Sumber: Data Primer, 2019

Tabel 2 menunjukkan bahwa sebelum diberikan pendidikan kesehatan tentang Parenting Skill, median pengetahuan responden tentang pembentukan karakter disiplin anak sebesar 7 (SD: \pm 1.404$)$, kemudian meningkat setelah diberikan pendidikan kesehatan tentang parenting skill menjadi $9(\mathrm{SD} \pm 1.115)$.

Tabel 3. Perubahan Pengetahuan Responden tentang Pembentukan Karakteristik Disiplin Anak Usia Preschool Sebelum dan Sesudah diberikan Parenting Skill

\begin{tabular}{lcc}
\hline $\begin{array}{l}\text { Pengetahuan tentang } \\
\text { Pembentukan } \\
\text { Karakter Disiplin }\end{array}$ & $\begin{array}{c}\text { Frek. } \\
\text { (N=41) }\end{array}$ & \% \\
Anak & & \\
\hline Nilai Meningkat & 27 & 65.9 \\
Nilai Tetap & 10 & 24.4 \\
Nilai Menurun & 4 & 9.7 \\
\hline Sum
\end{tabular}

Sumber: Data Primer, 2019

Berdasarkan tabel 3, didapatkan bahwa setelah diberikan parenting skill terjadi perubahan pengetahuan responden tentang pembentukan karakter disiplin anak, dimana perubahan terbanyak yaitu adanya peningkatan nilai pengetahuan sebanyak 27 responden atau sebesar $65.9 \%$. Sedangkan sebanyak 4 responden $(9.7 \%)$ mengalami penurunan nilai pengetahuan tentang pembentukan karakter disiplin anak.

Tabel 4. Perbedaan Pengetahuan Responden tentang Pembentukan Karakter Disiplin Anak Usia Preschool Sebelum dan Sesudah diberikan Parenting Skill Tahun 2019

\begin{tabular}{lcc}
\hline $\begin{array}{l}\text { Pengetahuan tentang } \\
\text { Pembentukan Karakter } \\
\text { Disiplin Anak }\end{array}$ & $\begin{array}{c}\text { Median } \\
( \pm \text { SD) }\end{array}$ & P value \\
\hline Sebelum Parenting Skill & 7 & $0.0001^{*}$ \\
& $( \pm 1.4)$ & \\
Sesudah Parenting Skill & $( \pm 1.1)$ & \\
\hline
\end{tabular}

Ket: *signifikansi $\alpha=0.05$

Sumber: Data Primer, 2019
Berdasarkan tabel 4 didapatkan bahwa median nilai pengetahuan responden tentang pembentukan karakter disiplin anak mengalami peningkatan. Secara statistik, peningkatan tersebut signifikan dengan nilai $\mathrm{p}$ sebesar $0.0001(<\alpha=0.05)$ dengan menggunakan uji peringkat Wilcoxon.

\section{PEMBAHASAN}

Karakter disiplin harus dibentuk mulai dari dini, hal ini memerlukan peran orang tua untuk menanamkan kebiasaan disiplin pada anak. Penelitian sebelumnya didapatkan bahwa peran orang tua dalam menanamkan karakter disiplin pada anak melalui metode pembiasaan, nasihat dan peraturan $^{(10,11)}$. Selain itu juga dapat ditambahkan metode lain seperti ganjaran dan hadiah ${ }^{(11)}$.

Peran orang tua dalam memberikan pembiasaan anak meliputi pembiasaan waktu dan kepribadian ${ }^{(12)}$. Upaya yang dapat dilakukan orang tua dalam menanamkan kebiasaan pada anak dapat dilakukan dengan memberikan contoh, mendampingi, dan melibatkan anak. Untuk itu, perlu peningkatan pengetahuan orang tua untuk melakukan pola pengasuhan yang baik.

Hasil penelitian ini menunjukkan bahwa terjadi peningkatan pengetahuan tentang pembentukan karakter disiplin anak setelah diberikan parenting skill. Hal ini sejalan dengan penelitian sebelumnya yang menyatakan bahwa pendidikan parenting dapat meningkatkan pengetahuan orang tua dalam menghadapi karakter anak ${ }^{(13,14)}$.

Pemahaman yang baik terkait metode parenting perlu diterapkan kepada anak. Penelitian sebelumnya didapatkan bahwa metode parenting berpengaruh terhadap kedisiplinan anak ${ }^{(15)}$. Anak yang mendapatkan metode parenting yang baik akan cenderung tumbuh dan berkembang menjadi pribadi yang memiliki karakter disiplin yang kuat. 
Meningkatnya pengetahuan yang terjadi setelah diberikan pelatihan parenting skill juga dapat dipengaruhi oleh usia responden yang sebagian besar masih relatif muda. Penelitian sebelumnya menyatakan bahwa kematangan usia mempengaruhi kesiapan diri menjadi orang tua dan semakin baik dalam pengasuhan terhadap anak ${ }^{(16)}$. Selain itu, usia yang relatif muda juga meningkatkan kemampuan dalam menerima informasi yang diberikan, sehingga pengetahuan terkait parenting skill dapat terserap dengan baik.

Faktor lain yang mempengaruhi cepatnya pemahaman orang tua terhadap informasi yang diberikan melalui parenting skill yaitu tingkat pendidikan. Sebagian besar responden berpendidikan baik, sehingga kemampuan menyerap dan menganalisis informasi yang diberikan semakin cepat dan baik. Hasil penelitian sebelumnya menyatakan bahwa tingkat pendidikan orang tua berpengaruh terhadap pola asuh terhadap anak ${ }^{(17)}$. Selain itu, penelitian lain menunjukkan bahwa terdapat hubungan antara tingkat pendidikan formal ibu dengan parenting self-efficacy yang membuat ibu lebih antusias dalam menerima informasi terkait pengasuhan anak yang baik dan benar ${ }^{(18)}$.

Peneliti beranggapan bahwa penggalian informasi terkait parenting dan pembentukan karakter disiplin anak, khususnya usia prasekolah, sangat penting agar dapat diterapkan pada anak.

\section{KESIMPULAN DAN SARAN}

Nilai pengetahuan responden sebelum diberikan parenting skill sudah baik dan setelah diberikan parenting skill menjadi semakin baik. Terdapat peningkatan yang bermakna nilai pengetahuan responden tentang pembentukan karakter disiplin pada anak. Diharapkan dengan peningkatan pengetahuan ini dapat diaplikasikan dalam pola pengasuhan anak, sehingga nantinya anak dapat tumbuh dan berkembang menjadi individu yang berkarakter disiplin yang kuat.

\section{UCAPAN TERIMA KASIH}

Ucapan terimakasih ditujukan kepada Kementerian Kesehatan RI yang telah memberikan bantuan biaya penelitian, sehingga penelitian ini dapat berjalan dengan lancar.

\section{DAFTAR PUSTAKA}

1. Tridhonanto A. Mengembangkan Pola Asuh Demokratis. Jakarta: Gramedia; 2014.

2. Batubara J. Pengembangan Karakter Jujur Melalui Pembiasaan. Jurnal Konseling dan Pendidikan. 2015;3(1):1.

3. Hapsari II. Psikologi Perkembangan Anak. Jakarta: Gramedia; 2016. 342 p.

4. Yaumi M. Pendidikan Karakter: Landasan, Pilar dan Implementasi. Jakarta: Prenada Media Group; 2014.

5. Indrijati H. Psikologi Perkembangan dan Pendidikan Anak Usia Dini: Sebuah Bunga Rampai. Jakarta: Prenada Media Group; 2016.

6. Global Report. Ending Violence in Childhood [Internet]. 2017 [cited 2019 Aug 7]. Available from: http://globalreport.knowviolenceinchildhoo d.org

7. KPAI. Maraknya Kasus Kekerasan pada Anak [Internet]. 2018 [cited 2019 Aug 7]. Available from: http://www.kpai.go.id

8. KPAID. Kekerasan Anak Masih Ada. 2017; Available from: http://kaltim.prokal.co/read/news/317590kekerasan-anak-masih-ada.html

9. Kalsum FY, Ervina I. Hubungan Parenting Skill dalam Melatih Disiplin Anak terhadap Motivasi Belajar Siswa di SD YIMA Bondowoso. Universitas Muhammadiyah Jember; 2019.

10. Ihsani N, Kurniah N, Suprapti A. Hubungan Metode Pembiasaan dalam Pembelajaran dengan Disiplin Anak Usia Dini. Jurnal Ilmiah Potensia. 2018;3(1):505.

11. Fatmah NA. Pola Penerapan Disiplin Anak Usia Dini di TK Kamala Bhayangkari 05 Sleman. Universitas Islam Negeri SUnan Kalijaga Yogyakarta; 2017.

12. Fitri A. AN, Jubaedah Y, Ningsih MP. Peran Orang Tua Dalam Penanaman Disiplin Pada Anak Usia Prasekolah 
Melalui Pembiasaan Di Kelurahan Cihaurgeulis Bandung. FamilyEdu: Jurnal Pendidikan Kesejahteraan Keluarga. 2017;2(2):81-91.

13. Erlanti MS, Mulyana N, Wibowo $\mathrm{H}$. Teknik Parenting Dan Pengasuhan Anak Studi Deskriptif Penerapan Teknik Parenting Di Rumah Parenting Yayasan Cahaya Insan Pratama Bandung. Prosiding Penelitian dan Pengabdian kepada Masyarakat. 2016;3(2):155-291.

14. Setijaningsih T, Matiningsih W. The Effect of Parenting Program Towards Knowledge and Attitude of Parents for Giving Fundamental Needs of Children in Early Age. Jurnal Ners dan Kebidanan (Journal of Ners and Midwifery). 2014;1(2):129-34.

15. Gaveni N. Pelaksanaan program parenting bagi orangtua dalam menumbuhkan perilaku keluarga ramah anak. Jurnal Pendidikan Luar Sekolah [Internet]. 2012;9(2):1-11. Available from: https://ejournal.upi.edu/index.php/pls/articl e/view/5425

16. Setyowati YD, Krisnatuti D, Hastuti D. Pengaruh Kesiapan Menjadi Orang Tua dan Pola Asuh Psikososial Terhadap Perkembangan Sosial Anak. Jurnal Ilmu Keluarga dan Konsumen. 2017;10(2):95106.

17. Maryam S. Gambaran Tingkat Pendidikan dan Pola Asuh Ibu pada Anak Usia Dini di Gampong Pante Gajah Kecamatan Matang Glumpang Dua Kabupaten Bireuen. Gender Equality: International Journal of Child and Gender Studies. 2017;3(2):67-76.

18. Pramudianti DC, Raden A, Suryaningsih EK. Hubungan tingkat pendidikan formal dengan parenting self-efficacy periode awal nifas pada ibu pasca sectio caesarea. Jurnal Kebidanan dan Keperawatan Aisyiyah. 2018;13(1):34-41. 